\title{
Lyapunov Function Based Flux and Speed Observer Using Advanced Non-linear Backstepping DVC for PWM-Rectifier Connected Wind-turbine-driven PM Generator
}

\author{
Youcef Saidi ${ }^{1 *}$, Abdelkader Mezouar ${ }^{1}$, Yahia Miloud², Mohammed Amine Benmahdjoub,3, \\ Brahim Brahmi ${ }^{4}$, Kamel Djamel Eddine Kerrouche ${ }^{5,6}$ \\ 1 Electro-Technical Engineering Laboratory (LGE), Faculty of Technology, Tahar Moulay University, P. O. B. 138, 20000 Ennasr, \\ Saida, Algeria \\ 2 Department of Electrical Engineering, Faculty of Technology, Tahar Moulay University, P. O. B. 138, 20000 Ennasr, Saida, Algeria \\ ${ }^{3}$ Electrical Energy Laboratory (EELAB), Department of Electromechanical, Systems and Metal Engineering, Faculty of Engineering \\ and Architecture, Ghent University, Sint-Pietersnieuwstraat 41, B 9000 Ghent, Belgium \\ ${ }^{4}$ Department of Electrical Engineering, École de Technologie Supérieure, P. O. B. H3C 1K3, 1100 Montreal, Canada \\ ${ }^{5}$ School of Automation on Science and Electrical Engineering, Beihang University, Haidian District, Beijing 100191, Xueyuan \\ Road 37, China \\ ${ }^{6}$ Satellite Development Center CDS, P. O. B. 4065, 31000 Ibn Rochd USTO, Oran, Algeria \\ * Corresponding author, e-mail: youcef.saidi@univ-saida.dz
}

Received: 09 August 2020, Accepted: 05 October 2020, Published online: 31 May 2021

\begin{abstract}
In this paper, modeling, and speed/position sensor-less designed Direct Voltage Control (DVC) approach based on the Lyapunov function are studied for three-phase voltage source Space Vector Pulse Width Modulation (SVPWM) Rectifier Connected to a Permanent Magnet Synchronous Generator (PMSG) Variable Speed Wind Power Generation System (VS-WPGS). This control strategy is based on voltage orientation technique without mechanical speed sensor. Advanced Non-linear Integral Backstepping Control (IBSC) of the Generator Side Converter (GSC) has the ability to have a good regulation of the DC link voltage to meet the requirements necessary to achieve optimal system operation, regardless of the disturbances caused by the characteristics of the drive train or some changes into the DC load. The estimation of the speed is based on Model Reference Adaptive System (MRAS) method. This method consists in developing two models one of reference and the other adjustable for the estimation of the two $d$ - $q$ axis components of the stator flux from the measurement of currents, the speed estimated is obtained by canceling the difference between the reference stator flux and the adjustable one using Lyapunov criterion of hyper-stability. Some results of simulation using Matlab/Simulink ${ }^{\circ}$ are presented, discussed to prove the efficiency and robustness of the system control policy for WPGS against external and internal perturbations.
\end{abstract}

\section{Keywords}

Wind Power Generation System (WPGS), Direct Voltage Control (DVC), Permanent Magnet Synchronous Generator (PMSG), Integral Backstepping Control (IBSC), Model Reference Adaptive System (MRAS), Lyapunov function

\section{Introduction}

In recent years, the $\mathrm{AC} / \mathrm{DC}$ converter applications are increasing in industry, commerce, and house utility. Traditionally, the main components of converters have been the diodes and thyristors bridges to rectify the AC power. These rectifiers have the advantages of being simple, robust, and having low cost [1]. However, they generate harmonics and reactive power in $\mathrm{AC}$ side, which results voltage distortion, poor power factor at power supply side and slowly varying rippled DC output at DC side. Therefore, a three-phase PWM rectifier is a more cunning solution for industrial applications, since it has more advantages such as adjustment and stabilization of DC-link voltage, sinusoidal line current, power factor control and bidirectional power flow [2, 3]. Wind Power Generation System (WPGS) is one of the most important industrial applications, among different wind power generation systems, Variable Speed Wind Power Generation System (VS-WPGS) have attracted great interests because of their high energy production efficiency and low torque spikes [4]. Nowadays, there are two types of generators 
which are used in large scale WPGS to transform the wind power into electrical energy, such as: DFIG (Doubly Fed Induction Generator) and PMSG (Permanent Magnet Synchronous Generator) [5]. Because of its ability to operate in all wind speed range and do not require excitation current, PM Generator shows good performance in wind farm. As the fast development of wind power technology, the efficiency of converter device in wind power generation system has become another knotty problem to improve wind power generation system performance [6].

The three-phase voltage source SVPWM-rectifier control based on DVC (Direct Voltage Control) issues are traditionally treated by fixed gain PI (Proportional Integral) controllers $[7,8]$. However, the fixed gain controllers are very sensitive to parameter variations and generally cannot provide good dynamic performance, such as discussed in [9]. So, the controller parameters have to be continually adapted. This problem can be solved by several adaptive control techniques such as: SMC (Sliding Mode Control) in [10]; FLC (Fuzzy Logic Control) in [11]; ANNC (Artificial Neural Networks Control) in [12]. A comparative study between polynomial RST and PI controllers is presented in [13].

One of the main obstacles to the development of WTGs is the design of low-computational time robust control strategies that can improve system efficiency while minimizing structural loading. Variable structure strategies with IBSC have evolved in recent years as a powerful control methodology of nonlinear systems with parameter uncertainties [14]. Among many positive features of IBSC are outstanding good performance against non-altered dynamics, good rejection of external disturbance, non-sensitivity to parameter changes, and rapid dynamic response [15].
In the area of renewable energies, many research papers focus on studying the effectiveness and reliability of the IBSC strategy, especially with regard to WPGSs, as we see in $[16,17]$ which focus on modeling and optimum power control of WPGs using backstepping control.

The contribution of this work is the combination between the three-phase voltage source SVPWM Rectifier and the WPG as a source of electrical energy, with the ability to properly control all subsystems without a mechanical speed sensor. The control without mechanical speed sensor for machine drive systems should continue to evolve towards more and more effective and innovative solutions for all problems associated with their operations that prevent effective performance. Therefore, many approaches for speed estimation have been investigated in the literature [18-20]. The Sensor-less control has been used with success in wind turbine systems [21,22]. The advantages of speed sensor-less generator WPGs are [23]:

- Reduced hardware complexity and lower cost;

- Reduces size of the drive machine;

- Elimination of the sensor cable;

- Better noise immunity;

- Increased reliability and fewer maintenance requirements.

In the literature, several speed estimation/observation techniques have been suggested and discussed. PM Generator rotor position/speed estimation based on fundamental-frequency model can be generally classified into two main categories: open-loop calculation and closed-loop observers [24], as shown in Fig. 1. Various types of the open-loop calculation category such as: Flux-based method,

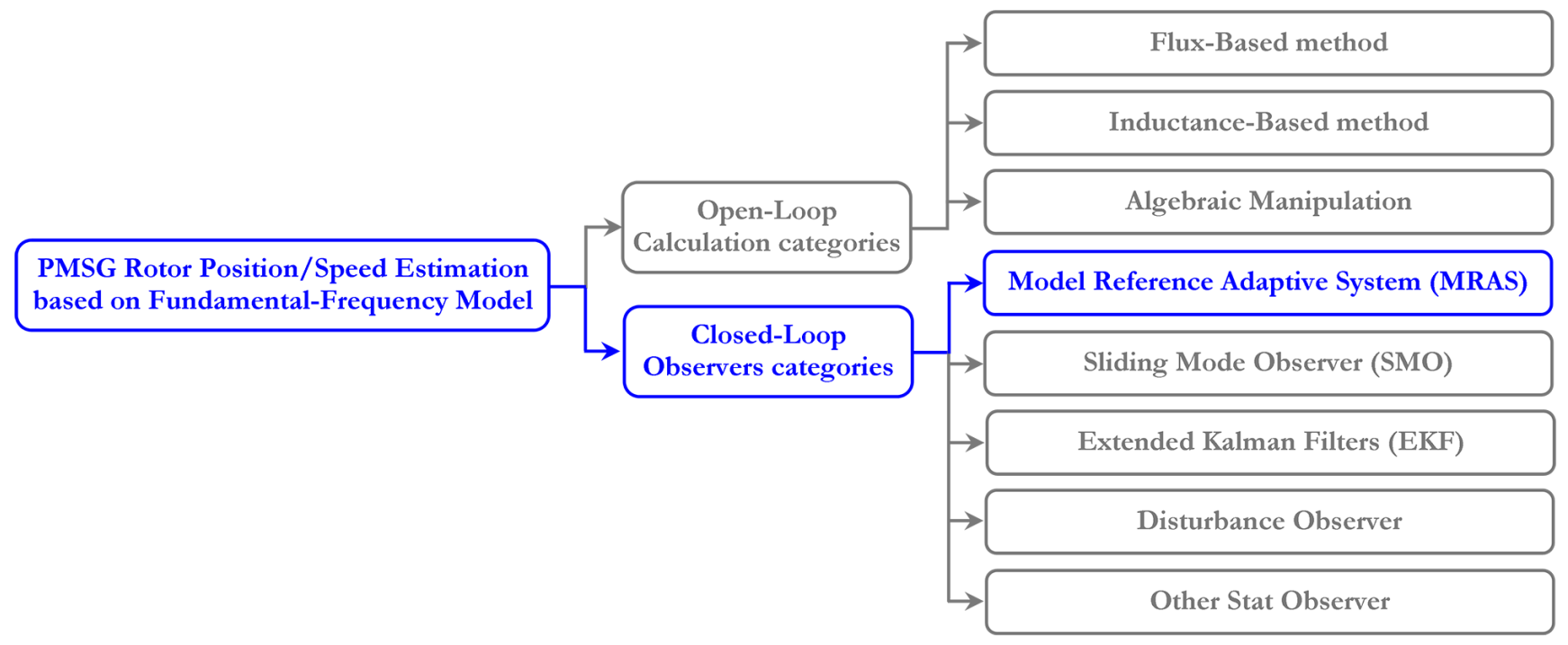

Fig. 1 Position/speed estimation schemes for PM Generators based on fundamental-frequency model 
Inductance-based method, and Algebraic manipulation. The closed-loop observers' methods have been widely utilized, due to their simplicity and flexibility. The Disturbance Observer (DO), Sliding Mode Observer (SMO), Model Reference Adaptive System (MRAS), Extended Kalman Filters (EKF) and other stat observer are the most common closed-loop observer's methods, as depicted in Fig. 1.

In this paper, a detailed dynamic model and a simple DVC strategy for a three-phase voltage source SVPWM rectifier with voltage orientation to improve the system's robustness and dynamic response of the DC-bus voltage is proposed. This control approach concentrates two main objectives: guaranteeing a speed sensor-less control estimator using Lyapunov function of hyper-stability and ensuring the control robustness against eventual disturbances.

\section{Modeling of studied system}

The topology of the WPGS presented in this study is depicted in Fig. 2. It consists of a wind turbine, a gearbox, a PM Generator, GSC (rectifier) and grid side converter (inverter). In our strategy studied, the converter on the generator is used to control the DC link voltage whatever the disturbances caused by the characteristics of the wind turbine drive train or the variation in the DC load.

\subsection{Wind speed modeling}

Wind speed generally has complex random variations, both deterministic effects (tower shadow and mean wind) and stochastic fluctuations over time due to turbulence. Generally, the stochastic and deterministic components are superimposed to form the following wind profile model [14], are (see Fig. 3):

$V(t)=V_{s}(t)+V_{t}(t)$,

where $V_{s}$ is the low frequency component and $V_{t}$ is the high frequency variations.

In this work we are interested only in much localized wind, the wind on the area swept by the rotor for a few seconds. In addition, to take into account the nature of

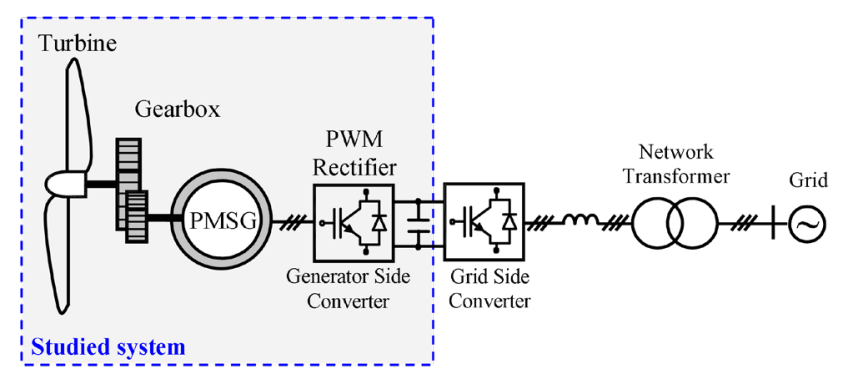

Fig. 2 Wind power generation chain based on PM Generator

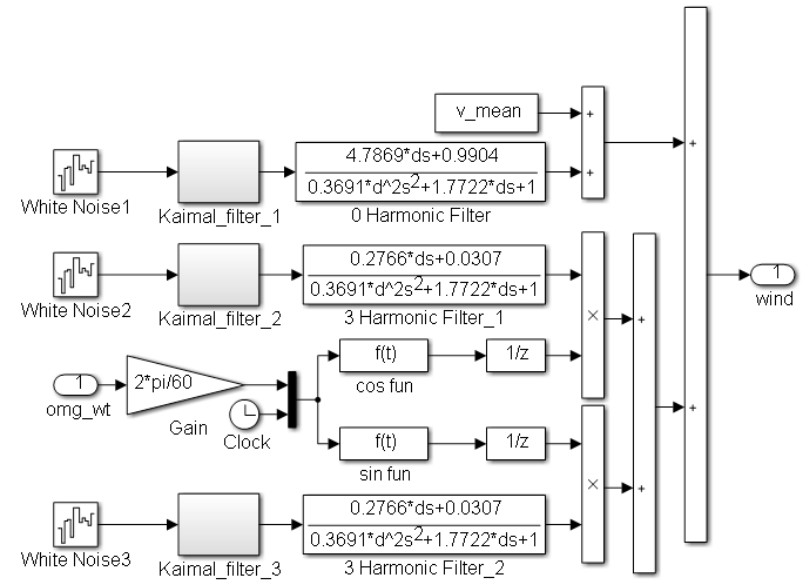

Fig. 3 RIS $\varnothing$ Simulink implementation of aerodynamic wind speed model

wind turbulent, stochastic models are also used. The turbulence spectrum endorsed the distribution of turbulent fluctuations energy, whose integral is determined by the intensity of the turbulence. The intensity of the turbulence is the following ratio [4]:

$I=\sigma / V_{0}$ with the variance $\sigma^{2}=\frac{1}{T} \int_{0}^{T} v(t) \mathrm{dt}$.

A Gaussian process can generate a turbulent wind distribution. Therefore, the V. Karman spectrum and Kaimal spectrum are the two models used, respecting the standards set by the IEC (International Electro-technical Commission) [4]:

V. Karman spectrum: $\varnothing(\omega)=\frac{K_{v}}{\left(1+(T \omega)^{2}\right)^{5 / 6}}$

Kaimal spectrum: $\varnothing(\omega)=\frac{K_{v}}{|1+T \omega|^{5 / 3}}$,

where $K_{v}$ : a variable related to the variance $T$, which determines the turbulence bandwidth. The Danish RISØ DTU laboratory for sustainable energy developed a wind model based Kaimal-spectrum. This model is implemented in MATLAB/Simulink ${ }^{\circledR}$, where it is clearly presented in [4], as shown in Fig. 3.

\subsection{Aerodynamic subsystem modeling}

The aerodynamic power $P_{a e r}$, which is converted by a wind turbine, is dependent on the power coefficient $C_{p}$ (Betz's factor). It is given by [25]:

$$
\left\{\begin{array}{l}
P_{a e r}=\frac{1}{2} C_{p}(\lambda, \beta) \rho \pi R^{2} V^{3} \\
C_{p}=c_{1}\left(\frac{c_{2}}{\lambda_{i}}-c_{3} \beta-c_{4}\right) \exp \left(\frac{-c_{5}}{\lambda_{i}}\right)+c_{6} \lambda
\end{array}\right.
$$


with $\frac{1}{\lambda_{i}}=\frac{1}{\lambda+0.08 \beta}-\frac{0.035}{\beta^{3}+1}$,

where $\rho$ is the air density, $R$ is the blade length and $V$ is the wind velocity.

The turbine torque $T_{\text {aer }}$ is the ratio of the output aerodynamic power $P_{\text {aer }}$ and the shaft speed $\Omega_{t}$ :

$T_{a e r}=\frac{P_{a e r}}{\Omega_{t}}$.

The power coefficient $C_{p}$ depends on the ratio $\lambda$ and the pitch angle $\beta$ is shown in Fig. 4.

In WPGS, the turbine usually associated to the generator shaft through a gearbox $G$. Ignoring the transmission losses, the shaft speed and torque of the WPGS, referred to the gearbox on the generator side, are given by [26]:

$T_{g}=T_{\text {aer }} / G ; \Omega_{t}=\Omega_{g} / G$,

where $\Omega_{g}$ is the generator-shaft speed and $T_{g}$ is the driving torque of the generator.

The power coefficient $C_{p}$ depends on the ratio $\lambda$ and the pitch angle $\beta$. This ratio is between linear speed at the tip of the blades and the wind speed:

$\lambda=\frac{\Omega_{t} R}{V}$.

By using the Eq. (3), the resulting mechanical equation is given by Eq. (6):

$J \dot{\Omega}_{g}=T_{g}-T_{e m}-f_{v} \Omega_{g}$,

where $J$ is the total moment of inertia, $f_{v}$ is the coefficient of viscous friction and $T_{e m}$ is the electromagnetic torque.

\subsection{Electrical subsystem modeling}

The circuit diagram of the three-phase two level voltage source rectifier structure connected to a PMSG wind energy conversion system is shown in Fig. 5. In order to set up math model, it's assumed that the filter reactor is linear, IGBT is ideal switch and lossless [27].

Where $i_{a s}, i_{b s}$ and $i_{c s}$, are phase currents, $C$ is smoothing capacitor across the DC bus, $R_{L}$ is the load resistance, and $i_{L}$ is load current.

The classical electrical equations of the PM generator and converter in the PARK frame are written in Eqs. (7), (8) [28]:

$V_{s}=\left[\begin{array}{c}v_{d s} \\ v_{q s}\end{array}\right]=\left[\begin{array}{l}-\left(R_{s}+R_{r}\right) i_{d s}-\left(L_{s}+L_{r}\right) \frac{d}{d t} i_{d s}+f_{e m, d} \\ -\left(R_{s}+R_{r}\right) i_{q s}-\left(L_{s}+L_{r}\right) \frac{d}{d t} i_{q s}+f_{e m, q}\end{array}\right]$,

$C \frac{d}{d t} v_{d c}=i_{d c}-i_{L}$

where $f_{e m, d}$ and $f_{e m, q}$ are the crosses coupling terms between the $d$-axis and $q$-axis:

$\left[\begin{array}{l}f_{e m, d} \\ f_{e m, q}\end{array}\right]=\left[\begin{array}{l}\omega\left(L_{s}+L_{r}\right) i_{q s} \\ -\omega\left(L_{s}+L_{r}\right) i_{d s}+\omega \varphi_{f}\end{array}\right]$,

where $R_{s}, L_{s}, R_{r}, R_{r}$, are the stator phase resistance and inductance, the rectifier line resistance and inductance, respectively and $\omega=\Omega_{g} P_{\text {PMSG }}$ is the electrical speed and $P_{\mathrm{PMSG}}$ is the pair pole number, $i_{d s}$ and $i_{q s}$ are the direct and quadrate axis stator currents, $\varphi_{f}$ is magnetic flux. $v_{d c}$ is the dc-bus voltage.

The electromagnetic torque is expressed as [27]:

$T_{e m}=\frac{3}{2} p_{\mathrm{PMSG}}\left[\left(L_{d}+L_{q}\right) i_{d s}+\varphi_{f}\right] i_{q s}$.

\section{Direct Voltage Control (DVC) strategy}

In this section, the principle of this control (DVC) based on voltage orientation consists of using a current loop, developed by analogy with the vector control of electrical

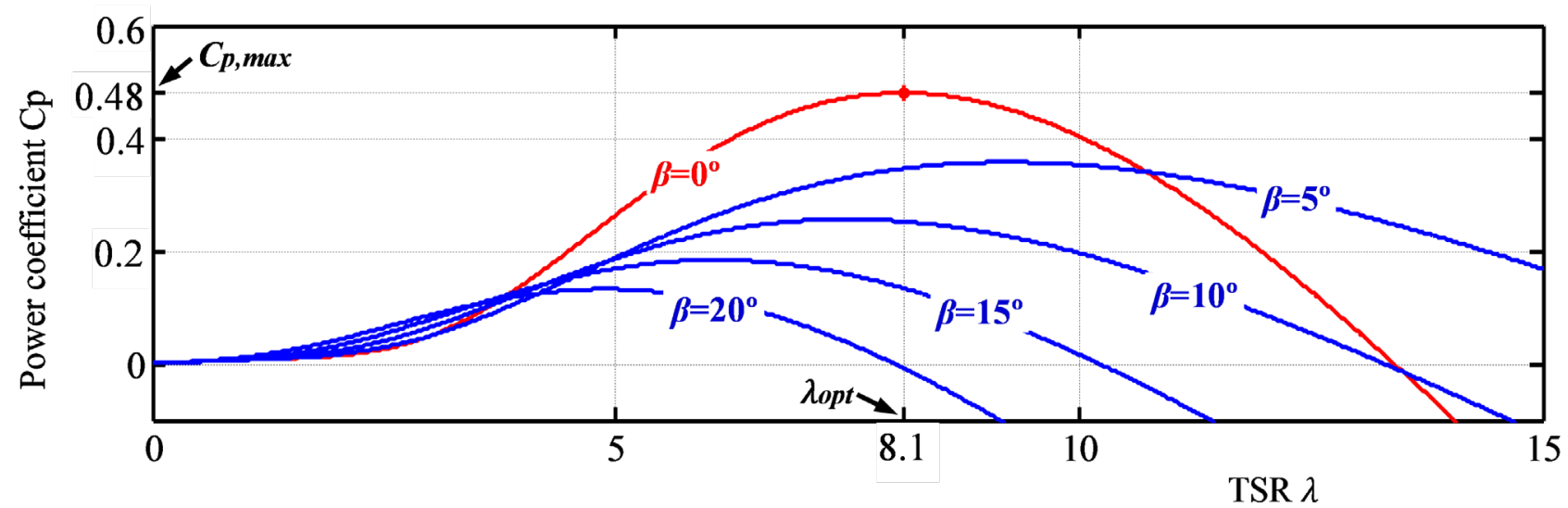

Fig. 4 WTGS power coefficient depending on the tip speed ratio under different blade orientation angles value 


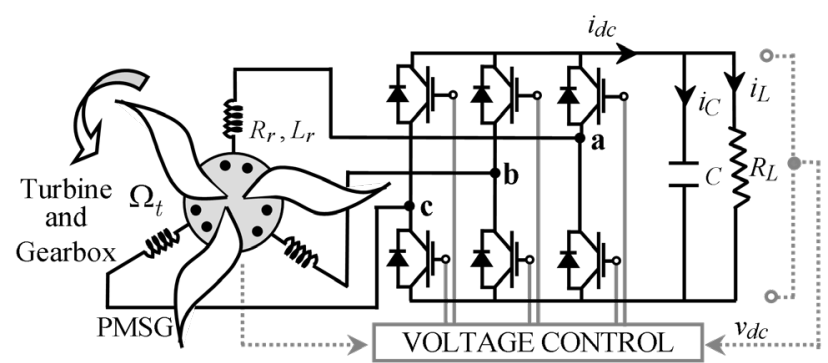

Fig. 5 Circuit schematic of SVPWM rectifier connected to PMSG WPGS

machines. It consists of orienting the current vector in the same direction as that of the voltage vector, by controlling the current vector in the two revolving axes $d$ and $q$.

Regarding Fig. 6, the current of the $d$-axis is set to zero while the reference current $i_{q s}$ is set by the DC link voltage regulator.

Once the rectifier is connected to an existing load, the transit of direct and quadrature axis currents must be controlled separately. To obtain a decoupled currents control of rectifier, the method based on voltage orientation can be regarded as the efficient one.

There are three control loops in the DVC based on voltage orientation strategy. The error between the reference dc-bus voltage $v_{d c}^{*}$ and the sampled dc-bus voltage $v_{d c}$ is processed by IBSC, which produces the reference quadrature axis current $i_{q s}^{*}$. Consequently, the proposed currents control can then be applied, as depicted in Fig. 7, considering that the direct and quadrature axis currents considered as variables to be controlled.

$$
\left[\begin{array}{c}
A_{s} \\
T_{s}
\end{array}\right]=\left[\begin{array}{ll}
\frac{1}{R_{r}+R_{s}} & \frac{L_{r}+L_{s}}{R_{r}+R_{s}}
\end{array}\right]^{T}
$$

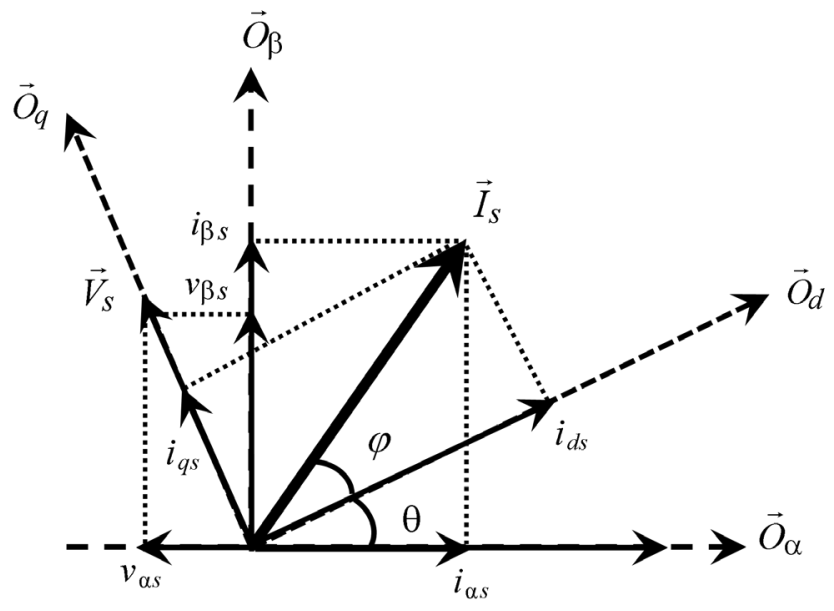

Fig. 6 Voltage orientation
As in the inner loops, $d$-axis currents loop and $q$-axis current loop use PI controllers to make the actual currents $\left(i_{d s}\right.$ and $\left.i_{q s}\right)$ track their reference values $\left(i_{d s}^{*}\right.$ and $\left.i_{q s}^{*}\right)$. Then, the errors are processed in two conventional PI controllers to produce the output signals of $v_{d s}^{*}$ and $v_{q s}^{*}$, after coordinates transformation, $v_{\alpha s}^{*}$ and $v_{\beta s}^{*}$ which can be obtained and used to produce switching signals $S_{a}, S_{b}$ and $S_{c}$ by two-level Space Vector Pulse With Modulation (SVPWM).

\section{Controller design}

\subsection{PI regulator synthesis}

In order to control the GSC used, we must perform a decoupling by compensation. To make the " $d$ " and " $q$ " axes completely independent. The PI (Proportional Integral) Corrector used to adjust the current is simple and quick to implement while offering acceptable performance. The proportional action serves to regulate the speed of the dynamics of the system, whereas the integral action makes it possible to eliminate the difference between the quantity of reference and that which one wishes to enslave.

The controller terms are calculated with a pole-compensation method. It is possible to generate reference voltages from given reference currents. Figs. 8 and 9 show the system scheme to be regulated by a PI corrector.

In fact, the errors $\left(i_{d s}^{*}-i_{d s}\right)$ and the errors $\left(i_{q s}^{*}-i_{q s}\right)$ are processed by the PI corrector to given reference voltages $v_{d s}^{*}$ and $v_{q s}^{*}$.

Using the Laplace transformation, the CLTF (ClosedLoop Transfer Function) is given as follows:

$\mathrm{CLTF}=\frac{\frac{A_{s}}{T_{s}}\left(K_{p, s} s+K_{i, s}\right)}{s^{2}+s\left(\frac{1+A_{s} K_{p, s}}{T_{s}}\right)+\frac{A K_{i, s}}{T_{s}}}$.

The calculated terms are in Table 1.

\subsection{IBSC regulator synthesis}

The integral backstepping approach is a robust non-linear method with the fast dynamic response in a wide range of operating conditions based on Lyapunov's theory [29]. The synthesis of this approach can be achieved in three successive steps:

1. Identification of the tracking error.

2. Choose of the Lyapunov's candidate function to ensure system stability.

3. Determination of equivalent control law. 


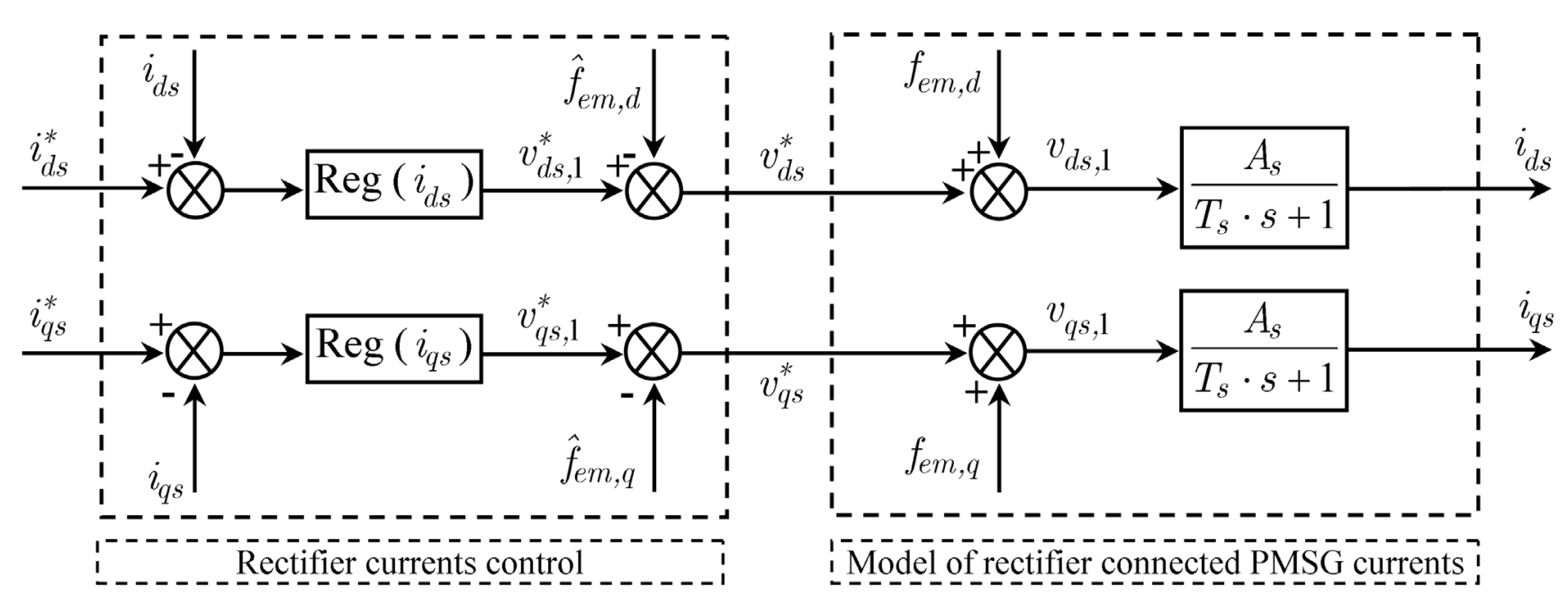

Fig. 7 Block diagram of direct and quadrature axis currents control

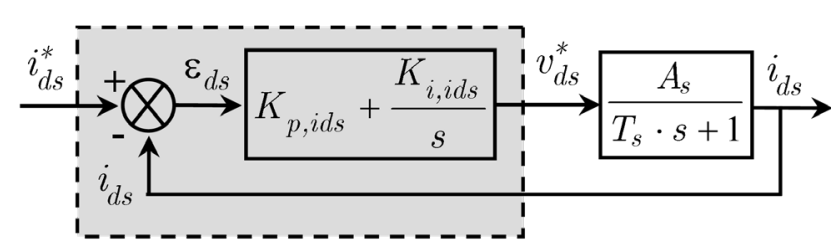

Fig. 8 Direct current regulation loop

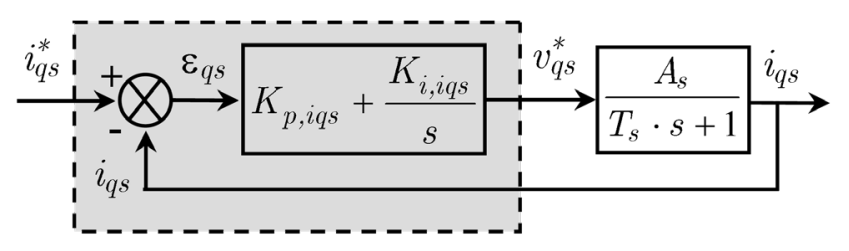

Fig. 9 Quadrature current regulation loop

Table 1 Calculated PI gains

\begin{tabular}{lcc}
\hline & $K_{p, \text { idqs }}$ & $K_{q, i d q s}$ \\
\hline PI controller & $\left(2 T_{s} \xi w_{0}-1\right) / A_{s}$ & $T_{s} w_{0}^{2} / A_{s}$ \\
Value & 24.9409 & $3.1415 \mathrm{e}+003$ \\
\hline
\end{tabular}

The non-linear backstepping control objective is to make the output track the reference trajectory. For a DC link voltage tracking system, the DC link voltage tracking error can be defined as

$Z_{v_{d c}}=v_{d c}^{*}-v_{d c}+k_{v_{d c}}^{\prime} \int_{0}^{t}\left(v_{d c}^{*}-v_{d c}\right) \mathrm{dt}$,

where $k_{v_{d c}}^{\prime} \int_{0}^{t}\left(v_{d c}^{*}-v_{d c}\right) \mathrm{dt}$ is an integral action added to DC link voltage error and $k_{v_{d c}}^{\prime}$ is a positive design constant.

This error derivative is:

$\dot{Z}_{v_{d c}}=\dot{v}_{d c}^{*}-\dot{v}_{d c}+k_{v_{d c}}^{\prime}\left(v_{d c}^{*}-v_{d c}\right)$
By neglecting the converter losses and taking into account the voltage orientation principle (Fig. 6), the dynamic model for the DC link circuit is obtained:

$P_{d c}=v_{d c} i_{d c}=v_{q s} i_{q s}$.

Substituting Eqs. (8) and (14) into Eq. (13) leads to:

$\dot{Z}_{v_{d c}}=\dot{v}_{d c}^{*}-\frac{v_{q s}}{C v_{d c}} i_{q s}+\frac{v_{d c}}{C R_{L}}+k_{v_{d c}}^{\prime}\left(v_{d c}^{*}-v_{d c}\right)$.

The resulting asymptotic stability of the Closed-Loop System (CLS) is guaranteed according to Lyapunov's stability theorem.

For the DC link voltage tracking error to be zero, first Lyapunov candidate stability function defined as

$V_{v_{d c}}=\frac{1}{2} Z_{v_{d c}}^{2}$

If this Lyapunov's candidate function is often positive and its derivative is often negative, then the error is going to be stable and have a tendency towards zero [14, 17].

Where $k$ is strictly positive constant, the derivative of the Lyapunov function is given by

$\dot{V}_{v_{d c}}=Z_{v_{d c}} \dot{Z}_{v_{d c}}=-k Z_{v_{d c}}^{2}<0$.

From Eqs. (12) and (15), the derivative of the Lyapunov function expression is obtained:

$-k Z_{v_{d c}}^{2}=Z_{v_{d c}}\left[\dot{v}_{d c}^{*}-\frac{v_{q s}}{C v_{d c}} i_{q s}+\frac{v_{d c}}{C R_{L}}+k_{v_{d c}^{\prime}}^{\prime}\left(v_{d c}^{*}-v_{d c}\right)\right]$.

Equation (19) can be written as

$-k Z_{v_{d c}}=\dot{v}_{d c}^{*}-\frac{v_{q s}}{C v_{d c}} i_{q s}+\frac{v_{d c}}{C R_{L}}+k_{v_{d c}^{\prime}}^{\prime}\left(v_{d c}^{*}-v_{d c}\right)$. 
Based on the backstepping design. The $i_{q s}$ current is chosen as virtual control elements which are known in backstepping terminology as a stabilizing function:

$i_{q s}^{*}=\frac{C v_{d c}}{v_{q s}}\left[\dot{v}_{d c}^{*}+\frac{v_{d c}}{C R_{L}}+k_{v_{d c}}^{\prime}\left(v_{d c}^{*}-v_{d c}\right)+k Z_{v_{d c}}\right]$.

\section{MRAS observer based Lyapunov function}

Speed estimation methods using MRAS have been described extensively in the literature for PMSM drive because of its simplicity in speed estimation and good results. In [30] we use the reactive power as the output value for the model to estimate the rotor speed, [31] propose a new MRAS approach that uses stator voltages and currents as state variables to estimate the rotor speed of PM Generator.

In Fig. 10 the MRAS observer uses two models to calculate a stator flux of the PMSG. One model is a reference model and the other one is an adaptive model. The error between these two models drives an adaptation mechanism that generates the mechanical speed by applying Lyapunov theory or Popov's criterion of hyper-stability. This speed is used in the adjustable model.

\subsection{Reference model}

From Eqs. (7) and (9), the stator voltage model is:

$\bar{V}_{s}=\left[\begin{array}{c}v_{d s} \\ v_{q s}\end{array}\right]=\left[\begin{array}{l}-\left(R_{s}+R_{r}\right) i_{d s}+\frac{d}{d t} \varphi_{d s}-\omega \varphi_{q s} \\ -\left(R_{s}+R_{r}\right) i_{q s}+\frac{d}{d t} \varphi_{q s}-\omega \varphi_{d s}\end{array}\right]$.

In the $d q$ reference frame, the reference stator flux model is expressed as follows:

$\bar{\varphi}_{s}=\bar{\varphi}_{s}^{*}=\left[\begin{array}{l}\varphi_{d s}^{*} \\ \varphi_{q s}^{*}\end{array}\right]=\left[\begin{array}{l}-\left(L_{s}+L_{r}\right) i_{d s}+\varphi_{f} \\ -\left(L_{s}+L_{r}\right) i_{d s}\end{array}\right]$.

\subsection{Adaptive model}

According to Eq. (21), the adaptive stator flux model is expressed by

$\hat{\varphi}_{s}=\left[\begin{array}{l}\hat{\varphi}_{d s} \\ \hat{\varphi}_{q s}\end{array}\right]=\left[\begin{array}{l}\int\left(v_{d s}+\left(R_{s}+R_{r}\right) \hat{i}_{d s}+\hat{\omega} \hat{\varphi}_{q s}\right) \mathrm{d} t \\ \int\left(v_{q s}+\left(R_{s}+R_{r}\right) \hat{i}_{q s}-\hat{\omega} \hat{\varphi}_{d s}\right) \mathrm{d} t\end{array}\right]$.

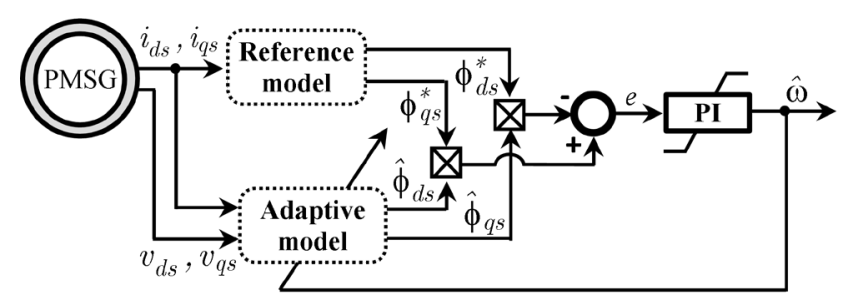

Fig. 10 Block diagram for MRAS observer based on stator flux
Note that the reference model is not related to the electrical pulsation, and therefore to the rotor speed. On the other hand, the adjustable model contains the speed information in its expression.

The adaptation algorithm is chosen so as to converge the adjustable model to the reference model by minimizing the error and having the stability of the system.

\subsection{Adaption mechanism}

The error between the estimated and reference $d-q$ axis stator currents are defined as

$e=\left[\begin{array}{l}e_{d} \\ e_{q}\end{array}\right]=\left[\begin{array}{l}\varphi_{d s}^{*}-\hat{\varphi}_{d s} \\ \varphi_{q s}^{*}-\hat{\varphi}_{q s}\end{array}\right]$

In making the difference between the reference model and the adjustable model, it becomes:

$\frac{d}{d t} e=\frac{d}{d t} \varphi_{s}^{*}-\frac{d}{d t} \hat{\varphi}_{s}$.

The state flux error component is:

$\dot{e}=\left[\begin{array}{l}\dot{e}_{d} \\ \dot{e}_{q}\end{array}\right]=\left[\begin{array}{l}-\frac{1}{T_{s}} \varphi_{d s}^{*}-\frac{1}{T_{s}} \varphi_{f}+v_{d s}-\left(L_{s}+L_{r}\right) \frac{d}{d t} i_{d s}+\hat{\omega} \hat{\varphi}_{q s} \\ -\frac{1}{T_{s}} \varphi_{q s}^{*}+v_{q s}-\left(L_{s}+L_{r}\right) \frac{d}{d t} i_{q s}+\hat{\omega} \hat{\varphi}_{d s}\end{array}\right]$.

The state flux errors are simplified as indicated in Eq. (27):

$\left\{\begin{array}{l}\dot{e}_{d}+\frac{1}{T_{s}} e_{d}=-\frac{1}{T_{s}} \hat{\varphi}_{d s}+\hat{\omega} \hat{\varphi}_{q s}+\frac{1}{T_{s}} \varphi_{f}+v_{d s}-\left(L_{s}+L_{r}\right) \frac{d}{d t} i_{d s} \\ \dot{e}_{q}+\frac{1}{T_{s}} e_{q}=-\frac{1}{T} \hat{\varphi}_{q s}+\hat{\omega} \hat{\varphi}_{d s}+v_{q s}-\left(L_{s}+L_{r}\right) \frac{d}{d t} i_{q s}\end{array}\right.$.

We obtain:

$\left\{\begin{array}{l}e_{d}\left(s+\frac{1}{T_{s}}\right)=-W_{d}\left(e_{d}, t\right)+f_{d}(t) \\ e_{q}\left(s+\frac{1}{T_{s}}\right)=-W_{q}\left(e_{q}, t\right)+f_{q}(t)\end{array}\right.$,

where

$f(t)=\left[\begin{array}{l}f_{d}(t) \\ f_{q}(t)\end{array}\right]=\left[\begin{array}{l}-\frac{1}{T_{s}} \hat{\varphi}_{d s}+\frac{1}{T_{s}} \varphi_{f}+v_{d s}-\left(L_{s}+L_{r}\right) \frac{d}{d t} i_{d s} \\ -\frac{1}{T_{s}} \hat{\varphi}_{q s}+v_{q s}-\left(L_{s}+L_{r}\right) \frac{d}{d t} i_{q s}\end{array}\right]$

and

$W(e, t)=\left[\begin{array}{l}W_{d}\left(e_{d}, t\right) \\ W_{q}\left(e_{q}, t\right)\end{array}\right]=\left[\begin{array}{l}-\hat{\omega}\left(e_{d}, t\right) \hat{\varphi}_{q s} \\ -\hat{\omega}\left(e_{q}, t\right) \hat{\varphi}_{d s}\end{array}\right]$. 
Equation (28) describes a feedback system explained in Fig. 11, having an open linear function as $L F(s)=T_{s} /\left(T_{s} s+1\right)$, and a non-linear function in the feedback chain where the inputs are $e_{d}, e_{q}$ and the outputs are $W(e, t)$.

As long as the global system consists of two subsystems, one linear and the other non-linear, the synthesis of the stability conditions requires that:

- The open linear function is null, positive, so: $\operatorname{Re}[L F(j w)]=\frac{T_{s}}{w^{2}+T_{s}^{2}}$ is positive $\forall w>0$.

- The adaptive mechanism included in the non-linear block must satisfy the criterion of the hyperstability of Popov's [32], the estimated speed of the rotor is given by

$$
\hat{\omega}(e, t)=A_{2}(e)+\int_{0}^{t} A_{1}(e) \mathrm{d} t .
$$

We pose:

$$
\left\{\begin{array}{l}
\omega_{p}\left(e_{d}, t\right)=A_{2}(e) \\
\omega_{i}\left(e_{d}, t\right)=\int_{0}^{t} A_{1}(e) \mathrm{d} t
\end{array} .\right.
$$

Where $\chi$ is Positive constant, the non-linear block verifies the inequality of Popov's defined by

$G=\int_{0}^{t} e_{d} W \mathrm{~d} t=G_{1}+G_{2}$,

with

$\int_{0}^{t} e_{d} W \mathrm{~d} t>-\chi^{2}$ in which, $\forall t \geq 0$,

where

$\left\{\begin{array}{l}G_{1}=\int e_{d} \hat{\varphi}_{d s}\left[\int_{0}^{t} A_{1}\left(e_{d}, t\right) \mathrm{d} t\right] \mathrm{d} t \\ G_{2}=\int e_{d} \hat{\varphi}_{q s}\left[A_{2}\right] \mathrm{d} t\end{array}\right.$

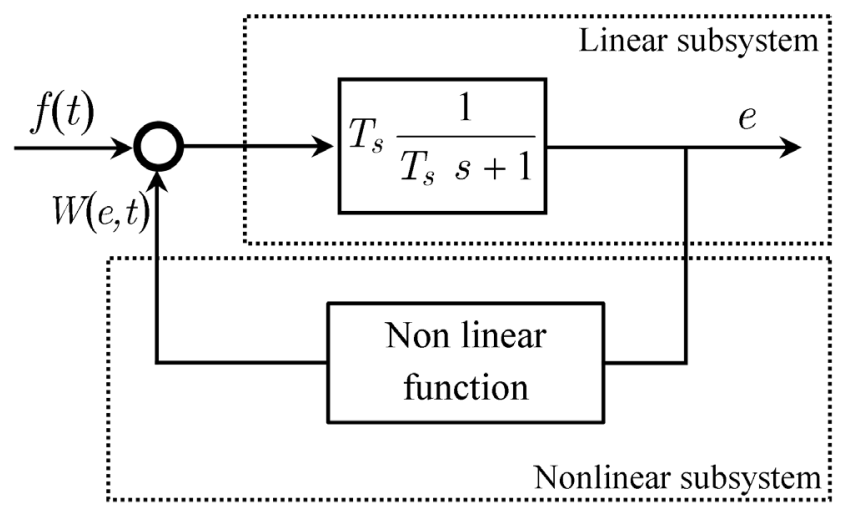

Fig. 11 Equivalent circuit diagram of MRAS
The solution of $G_{1}$ is given by the integral law adaptation $\omega_{i}\left(e_{d}, t\right)$, and the solution of $G_{2}$ is given by the proportional law adaptation $\omega_{p}\left(e_{d}, t\right)$ :

$\left\{\begin{array}{l}\omega_{i}\left(e_{d}, t\right)=K_{1} \int_{0}^{t} e_{d} \hat{\varphi}_{q s} \mathrm{~d} t+\omega(0) \\ \omega_{p}\left(e_{d}, t\right)=K_{2} e_{d} \hat{\varphi}_{q s}\end{array}\right.$ for $K_{1}, K_{2}>0$

$\omega\left(e_{d}, t\right)=K_{2} e_{d} \hat{\varphi}_{q s}+K_{1} \int_{0}^{t} e_{d} \hat{\varphi}_{q s} \mathrm{~d} t+\omega(0)$.

For $e_{q}=\left(\varphi_{q s}^{*}-\hat{\varphi}_{q s}\right)$ is the same way as $e_{d}$, we determine $\omega\left(e_{q}, t\right)$ which can be expressed as

$\omega\left(e_{q}, t\right)=-\left[K_{1}^{\prime} e_{q} \hat{\varphi}_{d s}+K_{2}^{\prime} \int_{0}^{t} e_{q} \hat{\varphi}_{d s} \mathrm{~d} t+\omega(0)\right]$

The estimated speed is finally given by

$\hat{\omega}=\omega\left(e_{d}, t\right)+\omega\left(e_{q}, t\right)$
$\hat{\omega}=K_{i} \int_{0}^{t}\left(e_{d} \hat{\varphi}_{q s}-e_{q} \hat{\varphi}_{d s}\right) d t+K_{p}\left(e_{d} \hat{\varphi}_{q s}-e_{q} \hat{\varphi}_{d s}\right)+\omega,(0)$

where

$e_{d} \hat{\varphi}_{q s}-e_{q} \hat{\varphi}_{d s}=\varphi_{q s}^{*} \hat{\varphi}_{d s}-\varphi_{d s}^{*} \hat{\varphi}_{q s}$.

The diagram of the proposed MRAS observer based Lyapunov function for the estimate speed based on the stator flux is shown in Fig. 10.

\section{Results and discussion}

Fig. 12 shows the block diagram of the proposed speed/ position sensor-less designed DVC approach scheme based on the Lyapunov function for three phase voltage Source SVPWM Rectifier Connected to a PMSG Variable Speed fixed-pitch WPGS based on IBSC.

To validate the proposed scheme presented in this paper, a series of simulation tests have been conducted under Matlab/ Simulink ${ }^{\circledR}$ environment. The main parameters of our simulation model are reported in the Appendix. All the simulation results were elaborated with a fixed-step size of 0.1 [ms] with a view to digital implementation in future works.

The $d q$ axis reference voltages $v_{d s}^{*}$ and $v_{q s}^{*}$ are used to determine the reference rectifier voltages $v_{\alpha s}^{*}$ and $v_{\beta s}^{*}$, which are directly obtained by applying the Alpha-beta transformation. These voltages are used for the SVPWM module in order to generate the IGBT gate control signals to drive the IGBT converter. The switching frequency of converter is set to $1[\mathrm{kHz}]$.

The proposed profile of the wind speed using RIS $\varnothing$ of the Danish DTU laboratory for sustainable energy is shown in Fig. 13 (a). Note that the estimated value of wind speed 


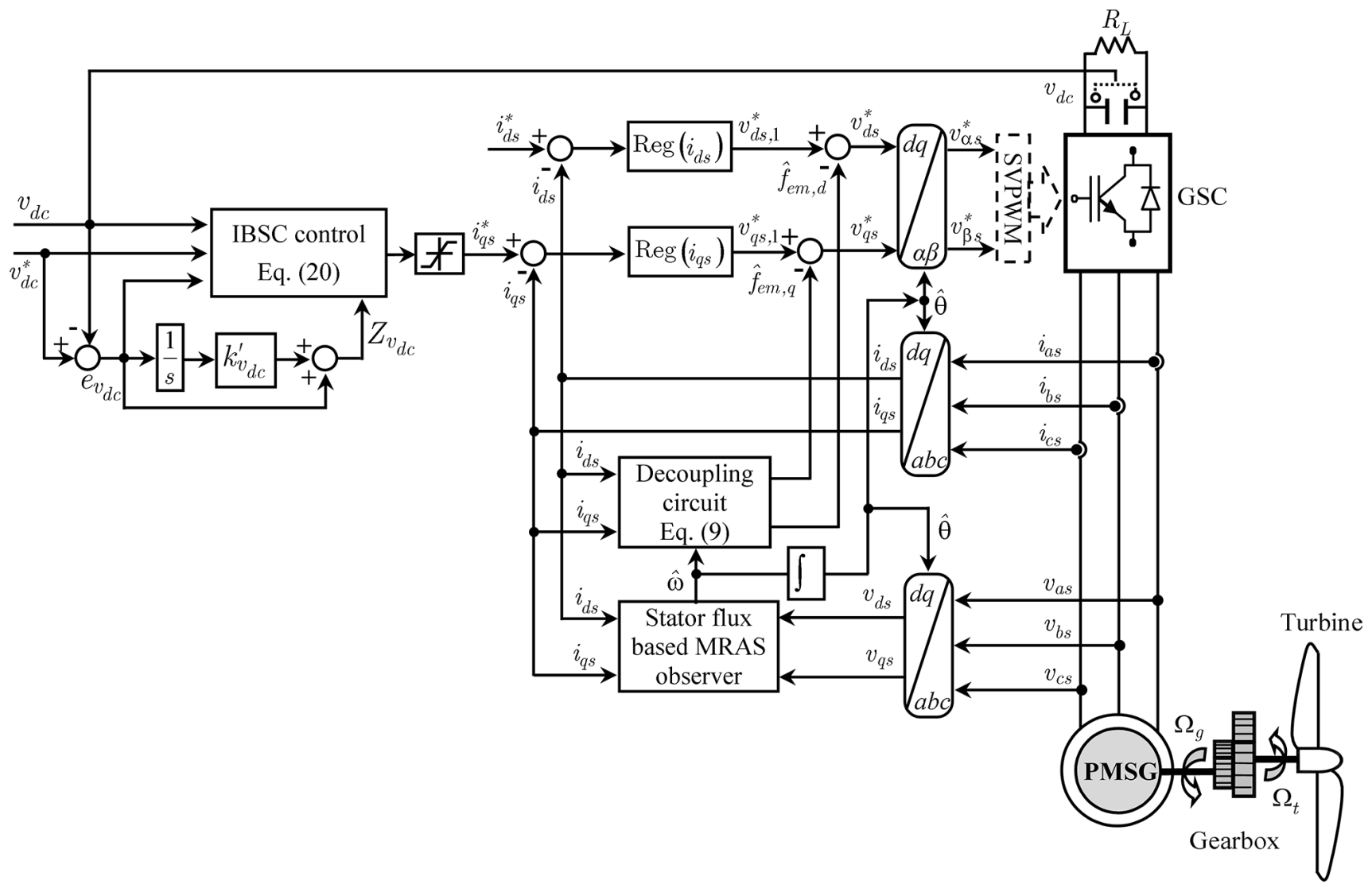

Fig. 12 Block diagram of the proposed DVC approach

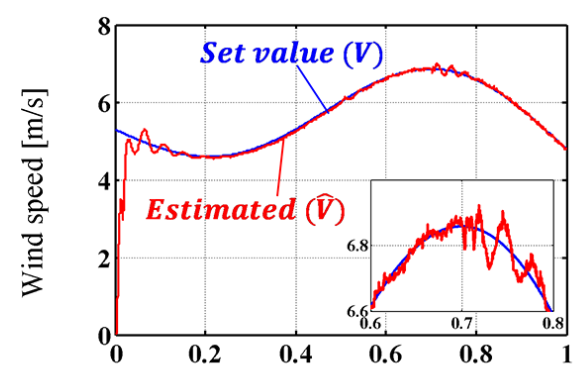

(a)

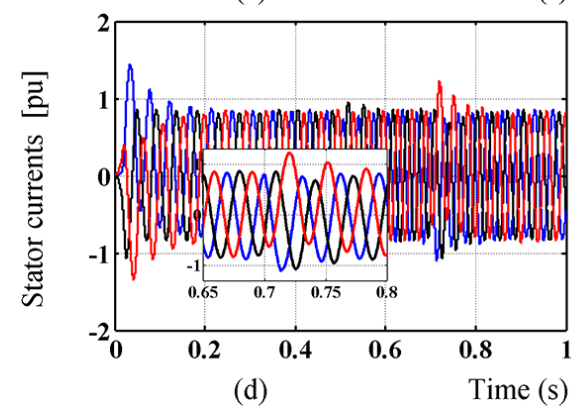

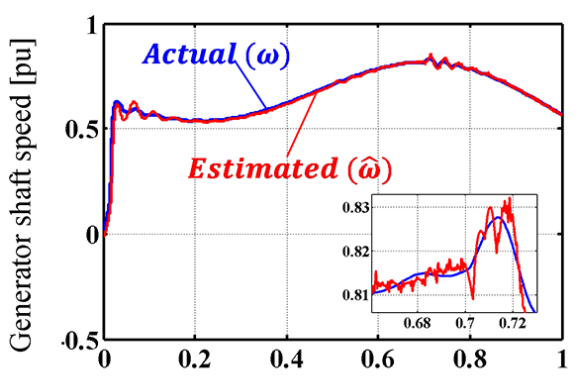

(b)

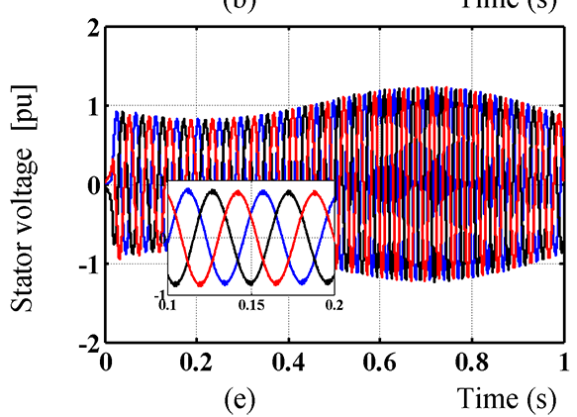

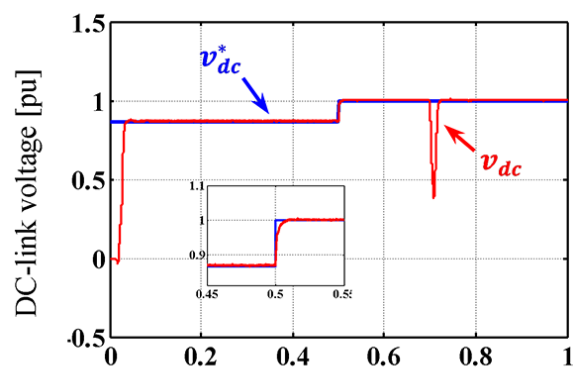

(c)

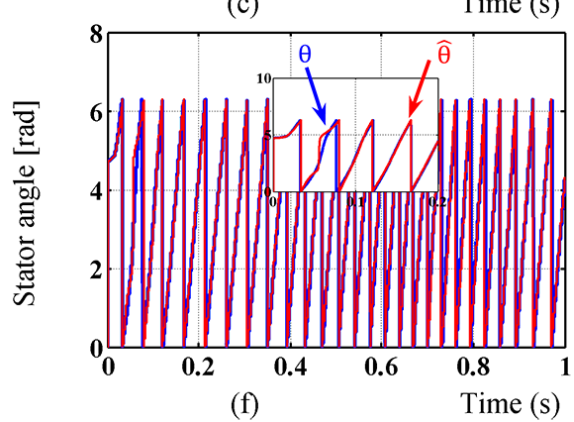

Fig. 13 Simulation results of the three-phase PWM Rectifier connected to a PMSG WPGS

coincides with its set value. The whole system is tested under load variation of $25 \%$ at $t=0.7$ [s], except this disturbance, the machine is considered as working over ideal conditions (no perturbations and no parameters variations).
Fig. 13 (b) shows the convergence of the estimated MRAS speed to the actual speed of the generator shaft, which is proportional to the curve of the wind speed. The behavior of rectifier is shown in Fig. 13 (c). It shows that the DC 
bus voltage is correctly regulated at the reference voltage, which means that the IBSC makes it possible to have very good performances (soft regulation and without exceeding). Fig. 13 (d), (e) shows, respectively, the stator currents and stator voltage, the simulation results show that the rectifier has good characteristics such as constant DC output voltage follows its reference value and sinusoidal input currents and voltage except the presence of a very small oscillations in the occurrence of the variation of the load.

Because of the proposed robust DVC approach, the stator current takes its natural sinusoidal alternative form and is not adapted to the variation of the wind speed.

The stator angle tracking is shown in Fig. 13 (f). It is noticed that the variations of load do not cause a large change in voltage angle. From Fig. 13 (f), it can be concluded that the speed and position of the permanent magnetic rotor are observed accurately, even in a dynamic process.

\section{References}

[1] Saidi, Y., Mezouar, A., Miloud, Y., Benmahdjoub, M. A. "A Robust Control Strategy for Three Phase Voltage t Source PWM Rectifier Connected to a PMSG Wind Energy Conversion System", In: 2018 International Conference on Electrical Sciences and Technologies in Maghreb (CISTEM), Algiers, Algeria, 2018, pp. 1-6. https://doi.org/10.1109/CISTEM.2018.8613359

[2] Khaburi, D. A., Nazempour, A. "Design and simulation of a PWM rectifier connected to a PM generator of micro turbine unit", Scientia Iranica, 19(3), pp. 820-828, 2012.

https://doi.org/10.1016/j.scient.2011.09.017

[3] Singh, B., Singh, B. N., Chandra, A., Al-Haddad, K., Pandey, A., Kothari, D. P. "A review of three-phase improved power quality AC-DC converters", IEEE Transactions on Industrial Electronics, 51(3), pp. 641-660, 2004.

https://doi.org/10.1109/TIE.2004.825341

[4] Saidi, Y., Mezouar, A., Miloud, Y., Brahmi, B., Kerrouche, K. D. E., Benmahdjoub, M. A. "Adaptive Maximum Power Control Based on Optimum Torque Method for Wind Turbine by Using Fuzzy-Logic Adaption Mechanisms during Partial Load Operation", Periodica Polytechnica Electrical Engineering and Computer Science, 64(2), pp. 170-178, 2020.

https://doi.org/10.3311/PPee.15155

[5] Anaya-Lara, O., Jenkins, N., Ekanayake, J. B., Cartwright, P., Hughes, M. "Wind Energy Generation: Modelling and Control", John Wiley \& Sons, West Sussex, UK, 2011.

[6] Mazouz, L., Zidi, S. A., Hafaifa, A., Hadjeri, S., Benaissa, T. "Optimal Regulators Conception for Wind Turbine PMSG Generator Using Hooke Jeeves Method", Periodica Polytechnica Electrical Engineering and Computer Science, 63(3), pp. 151-158, 2019. https://doi.org/10.3311/PPee.13548

[7] Wang, X., Huang, K., Yan, S., Xu, B. "Simulation of Three-Phase Voltage Source PWM Rectifier Based on Direct Current Control", In: 2008 Congress on Image and Signal Processing, Hainan, China, 2008, pp. 194-198.

https://doi.org/10.1109/CISP.2008.705

\section{Conclusions}

Based on the Lyapunov stability theory, a comprehensive model and robust DVC strategy was presented for a threephase voltage source PWM-rectifier based on a PMSG wind turbine. The rotor speed and stator angle observer accuracy are guaranteed through the stator flux observer. The proposed MRAS observer-based robust DVC control demonstrated very good performance, especially; it is robust under wind speed variation, external load disturbances and output DC link voltage tracking. On the other hand, it has been proven that the use of the integral backstepping control can provide a good regulation of output $\mathrm{DC}$ voltage; the AC current and voltage take its perfectly sinusoidal natural form.

Future work is oriented at experimental validation, including discrete time version and sliding mode flux of speed/position sensor-less observer.

[8] Hartani, K., Miloud, Y. "Control Strategy for Three Phase Voltage Source PWM Rectifier Based on the Space Vector Modulation", Advances in Electrical and Computer Engineering, 10(3), pp. 61-65, 2010. https://doi.org/10.4316/AECE.2010.03010

[9] Kumar, M. P., Mahavishnu, K. B. P. "An illustrative study on the control strategies for the boost type of three-phase bridge PWM rectifiers", In: 2016 International Conference on Electrical, Electronics, and Optimization Techniques (ICEEOT), Chennai, India, 2016, pp. 4691-4698.

https://doi.org/10.1109/ICEEOT.2016.7755610

[10] Fnaiech, M. A., Trabelsi, M., Khalil, S., Mansouri, M., Nounou, H., Abu-Rub, H. "Robust sliding mode control for three-phase rectifier supplied by non-ideal voltage", Control Engineering Practice, 77, pp. 73-85, 2018.

https://doi.org/10.1016/j.conengprac.2018.05.003

[11] Saidi, Y., Mezouar, A., Miloud, Y., Benmahdjoub, M. A., Yahiaoui, M. "Fuzzy Logic Based Robust DVC Design of PWM Rectifier Connected to a PMSG WECS under wind/load Disturbance Conditions", International Journal of Energetica (IJECA), 4(1), pp. 37-43, 2019.

https://doi.org/10.47238/ijeca.v4i1.84

[12] Li, S., Fairbank, M., Johnson, C., Wunsch, D. C., Alonso, E., Proao, J. L. "Artificial Neural Networks for Control of a GridConnected Rectifier/Inverter Under Disturbance, Dynamic and Power Converter Switching Conditions", IEEE transactions on neural networks and learning systems, 25(4), pp. 738-750, 2014. https://doi.org/10.1109/TNNLS.2013.2280906

[13] Sant'Ana, W. C., Salomon, C. P., Lambert-Torres, G., da Silva, L. E. B., Bonaldi, E. L., de Oliveira, L. E. L., Santana Filho, J., Mollica, D. "Modeling and control of AC current and DC voltage of PWM converters using polynomial RST and PI controllers", In: 2017 Brazilian Power Electronics Conference (COBEP), Juiz de Fora, Brazil, 2017, pp. 1-7. https://doi.org/10.1109/COBEP.2017.8257282 
[14] Saidi, Y., Mezouar, A., Miloud, Y., Kerrouche, K. D. E., Brahmi, B., Benmahdjoub, M. A. "Advanced non-linear backstepping control design for variable speed wind turbine power maximization based on tip-speed-ratio approach during partial load operation", International Journal of Dynamics and Control, 8, pp. 615-628, 2020. https://doi.org/10.1007/s40435-019-00564-3

[15] Xiong, P., Sun, D. "Backstepping-Based DPC Strategy of a Wind Turbine-Driven DFIG Under Normal and Harmonic Grid Voltage", IEEE Transactions on Power Electronics, 31(6), pp. 4216-4225, 2016. https://doi.org/10.1109/TPEL.2015.2477442

[16] Doumi, M., Aissaoui, A. G., Tahour, A., Abid, M., Tahir, K., "Nonlinear Integral Backstepping Control of Wind Energy Conversion System Based on a Double-Fed Induction Generator", Przegląd Elektrotechniczny, 92(3), pp. 130-135, 2016. https://oi.org/10.15199/48.2016.03.32

[17] Al Tahir, A. A. R. "Semi-global output feedback nonlinear stabilization of variable speed grid connected direct drive wind turbine generator systems", International Journal of Dynamics and Control, 6(1), pp. 233-261, 2018. https://doi.org/10.1007/s40435-016-0288-0

[18] Mezouar, A., Fellah, M. K., Hadjeri, S. "Adaptive sliding-mode-observer for sensorless induction motor drive using two-time-scale approach", Simulation Modelling Practice and Theory, 16(9), pp. 1323-1336, 2008. https://doi.org/10.1016/j.simpat.2008.06.009

[19] Fantino, R., Solsona, J., Busada, C. "Nonlinear observer-based control for PMSG wind turbine", Energy, 113, pp. 248-257, 2016. https://doi.org/10.1016/j.energy.2016.07.039

[20] Ammar, A., Kheldoun, A., Metidji, B., Ameid, T., Azzoug, Y. "Feedback linearization based sensorless direct torque control using stator flux MRAS-sliding mode observer for induction motor drive", ISA transactions, 98, pp. 382-392, 2020. https://doi.org/10.1016/j.isatra.2019.08.061

[21] Kumar, R., Das, S. "Model Reference Adaptive System-Based Sensorless Speed Control of Grid-Connected Doubly Fed Induction Generator in Wind Energy Conversion System", Iranian Journal of Science and Technology, Transactions of Electrical Engineering, 44, pp. 129-140, 2020. https://doi.org/10.1007/s40998-019-00196-5

[22] Yin, X., Zhao, X. "Sensorless Maximum Power Extraction Control of a Hydrostatic Tidal Turbine Based on Adaptive Extreme Learning Machine", IEEE Transactions on Sustainable Energy, 11(1), pp. 426-435, 2020. https://doi.org/10.1109/TSTE.2019.2894064

[23] Abdelrahem, M., Hafni, A. E., Kennel, R., Hackl, C. M. "Predictive phase locked loop for sensorless control of PMSG based variable-speed wind turbines", In: 2017 IEEE International Symposium on Sensorless Control for Electrical Drives (SLED), Catania, Italy 2017, pp. 151-156. https://doi.org/10.1109/SLED.2017.8078446

[24] Zhao, Y., Wei, C., Zhang, Z., Qiao, W. "A Review on Position/ Speed Sensorless Control for Permanent-Magnet Synchronous Machine-Based Wind Energy Conversion Systems", IEEE Journal of Emerging and Selected Topics in Power Electronics, 1(4), pp. 203-216, 2013.

https://doi.org/10.1109/JESTPE.2013.2280572
[25] Saidi, Y., Mezouar, A., Miloud, Y., Benmahdjoub, M. A., Yahiaoui, M. "Modeling and Comparative Study of Speed Sensor and Sensor-less based on TSR-MPPT Method for PMSG-WT Applications", International Journal of Energetica (IJECA), 3(2), pp. 6-12, 2018. https://doi.org/10.47238/ijeca.v3i2.69

[26] Saidi, Y., Mezouar, A., Miloud, Y., Yahiaoui, M., Benmahdjoub, M. A. "Modeling and Adaptive Power Control-Designed based on Tip Speed Ratio method for Wind Turbines", Przegląd Elektrotechniczny (Electrical Review), 95(6), pp. 40-46, 2019.

https://doi.org/10.15199/48.2019.06.08

[27] Saidi, Y., Mezouar, A., Miloud, Y. "Comportement Dynamique d'un Système de Conversion d'Énergie Éolienne à Base d'une Génératrice Synchrone à Aimants Permanents en Cas de Creux de Tension du Réseau Électrique" (Dynamic Behavior of a Wind Power Conversion System Based on a Permanent Magnet Synchronous Generator in the Event of Power Network Voltage Dips), Revue Roumaine des Sciences Techniques-Serie Electrotechnique et Energetique, 64(4), pp. 331-339, 2019. [online] Available at: http://revue.elth.pub.ro/index.php?action $=$ details $\&$ id $=867$ [Accessed: 20 July 2020] (in French)

[28] Nasiri, M., Milimonfared, J., Fathi, S. H. "A review of low-voltage ride-through enhancement methods for permanent magnet synchronous generator based wind turbines", Renewable and sustainable energy reviews, 47, pp. 399-415, 2015. https://doi.org/10.1016/j.rser.2015.03.079

[29] Wang, F., Chen, W., Dai, H., Li, J., Jia, J. "Backstepping control of a quadrotor unmanned aerial vehicle based on multi-rate sampling", Science China Information Sciences, 62(1), Article number: 19203, 2019. https://doi.org/10.1007/s11432-018-9542-3

[30] Kerrouche, K. D., Mezouar, A., Boumediene, L., Van den Bossche, A. "Speed sensor-less and robust power control of grid-connected wind turbine driven doubly fed induction generators based on flux orientation", The Mediterranean Journal of Measurement and Control, 12(3), pp. 606-618, 2016. [online] Available at: https://biblio.ugent.be/publication/7275252/ file/8517868.pdf [Accessed: 20 July 2020]

[31] Abdelrahem, M., Hack1, C., Farhan, A., Kennel, R. "Finite-Set MRAS Observer for Encoderless Control of PMSGs in Wind Turbine Applications", In: 2019 IEEE Conference on Power Electronics and Renewable Energy (CPERE), Aswan City, Egypt, 2019, pp. 431-436. https://doi.org/10.1109/CPERE45374.2019.8980023

[32] Schauder, C. "Adaptive speed identification for vector control of induction motors without rotational transducers", In: Conference Record of the IEEE Industry Applications Society Annual Meeting, San Diego, CA, USA, 1989, pp. 493-499. https://doi.org/10.1109/IAS.1989.96696 


\section{Appendix}

In this part, simulations are investigated with a $1.5 \mathrm{MW}$ generator WPGS [27]. The parameters of our system are presented in Table 2.

Table 2 Parameters of PMSG WPGS

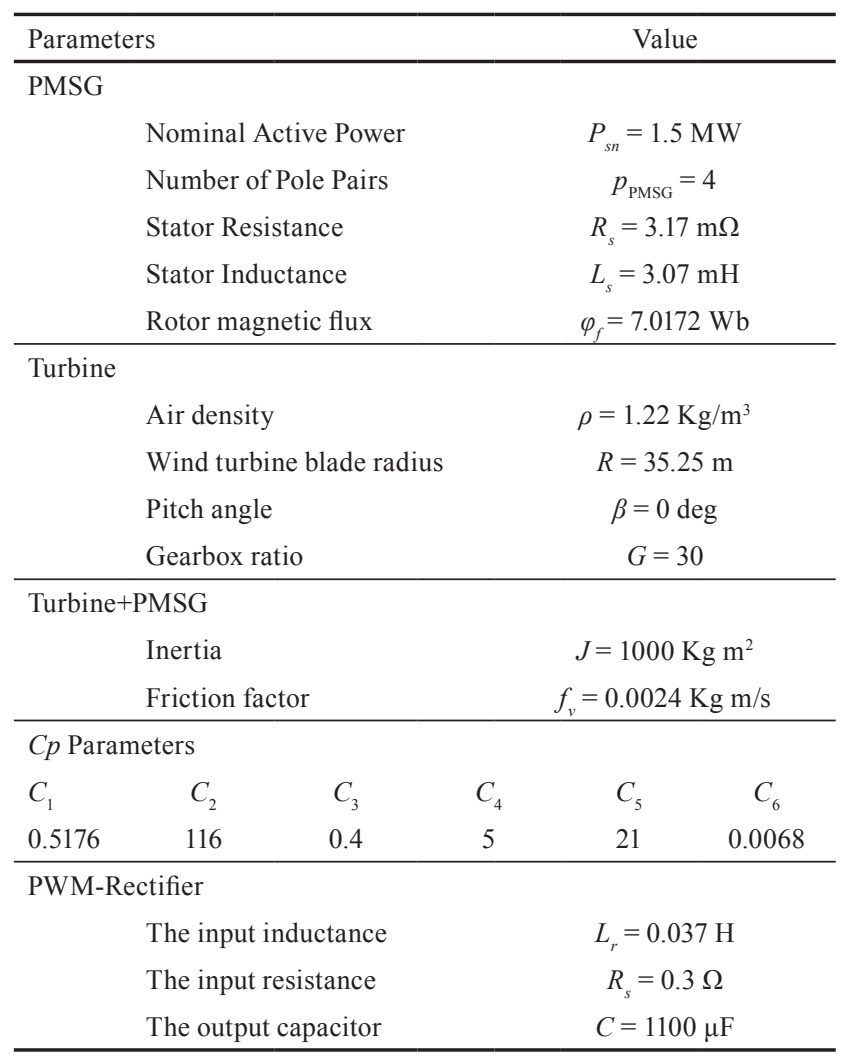

